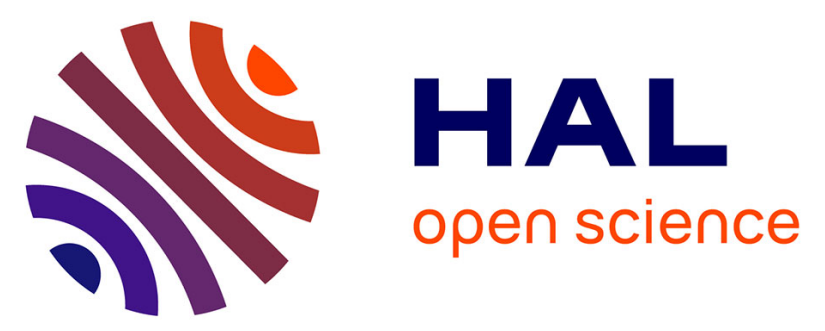

\title{
Real-time Microseismic Monitoring: Automatic Wave Processing and Multilayered Velocity Model for Accurate Event Location
}

\author{
Gloria Senfaute, Pascal Bigarre, Jean-Pierre Josien
}

\section{To cite this version:}

Gloria Senfaute, Pascal Bigarre, Jean-Pierre Josien. Real-time Microseismic Monitoring: Automatic Wave Processing and Multilayered Velocity Model for Accurate Event Location. International symposium of the international society for rock mechanics (EUROCK 1994), Aug 1994, Delft, Netherlands. pp.631-638. ineris-00971903

HAL Id: ineris-00971903

https://hal-ineris.archives-ouvertes.fr/ineris-00971903

Submitted on 3 Apr 2014

HAL is a multi-disciplinary open access archive for the deposit and dissemination of scientific research documents, whether they are published or not. The documents may come from teaching and research institutions in France or abroad, or from public or private research centers.
L'archive ouverte pluridisciplinaire HAL, est destinée au dépôt et à la diffusion de documents scientifiques de niveau recherche, publiés ou non, émanant des établissements d'enseignement et de recherche français ou étrangers, des laboratoires publics ou privés. 


\title{
Real-time microseismic monitoring: Automatic wave processing and multilayered velocity model for accurate event location \\ G.Senfaute, P.Bigarré \& J.P.Josien, INERIS, Nancy, France \\ E. Mathieu, Provence Colliery, Meyreuil, France
}

\begin{abstract}
At the Provence colliery, France, the remote microseismic monitoring used for the prevention of dynamic phenomena is an integral part of a strategy for exploring zones where there are risks of violent instability or rockbursts. Precise location, in real time, of the hypocentres associated with daily microseismic activity is one of the main objectives in the interpretation of data to optimise countermeasures. A study has been carried out with the purpose of calibrating an inclined wave propagation multilayered model. This article describes the operational microseismic monitoring network, the method used to calibrate the velocity model, the results obtained and the undeniable contribution which it makes to the quality of data interpretation.
\end{abstract}

\section{INTRODUCTION}

Mine-induced seismicity is a well-known phenomena wherever mining activities take place at great depths. At Provence colliery, France, longwall mining at 1100 meters deep induces numerous, daily tremors, triggered by the caving process above the tabular orebody. Many factors play an important part in this seismic activity, characterizing the response of the rock mass to the voids created underground. These factors are usually identified as the geology, the tectonics, the natural state of stress, and the mine layout, all playing a significant contribution to the rate of seismic energy released. In order to improve rockburst prevention and get insight into the rock mass behaviour in all areas undergoing development or human activities, a microseismic monitoring network was installed in 1992. This network has been regularly improved since, in order to integrate this seismic activity in a daily report submitted to the mine management. This information is part of the full quality control of the data collected underground for decisions to be taken in matter of safety countermeasures.

Concerning 24 hour seismic data collection, the network permits qualification and quantification of the seismic activity following the different districts of the mine in activity. It provides the calculated hypocenter and local magnitude of the tremors recorded by the seismic monitoring system installed as well as full ground motions parameters. Since more than 100 events might be recorded during a day, specific, powerful software has been installed in order to provide for high quality, real time microseismic monitoring integrating on-line and off-line full waveform processing and analysis.

\section{DESCRIPTION OF THE MICROSEISMIC MONITORING SYSTEM}

\subsection{Data acquisition system}

The data acquisition network consists of eight stations of the vertical uniaxial geophone type and a tridirectional station (natural frequency $=1 \mathrm{~Hz}$ ). Four vertical stations and the tridirectional station are distributed at the surface. The data transmission from this surface network to the central site is by radio, while four underground stations are connected to the site by cables (Fig.1)

The central automatic data acquisition and processing system was designed for maximum reliability of the processing of microseismic events in quasi-real time. This system is described in detail in (Bigarre et al, 1994). Two $P C / 386$ compatible computers, arranged in parallel, perform the data acquisition, in a Master/ Salve relationship, at a sampling frequency of $155 \mathrm{~Hz}$. For triggering to take place, a combination of criteria is validated. The PC Master then executes acquisition of the signal during the parameterised time and switches to slave mode, the slave PC itself switching to master mode (Fig.2). This enables automatic preprocessing to be carried out for the production of a report and permits 


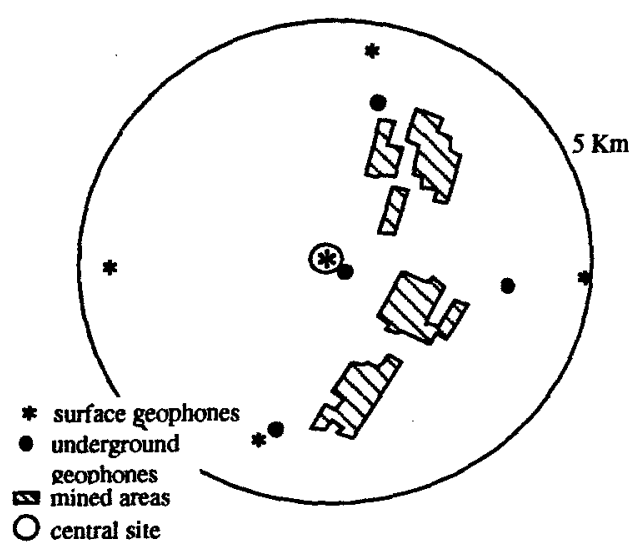

Figure 1: geometry of the seismic array with mined layout mapped

network transmission to a multitask machine for complete processing of the immediate signal. The time needed for these latter operations (a few seconds) is distinctly smaller than the acquisition time itself which means that the system is never blind. This protocol offers the advantage of providing the necessary operational reliability. In fact, this system automatically detects the disablement of one of the two computers (change of configuration, intervention, breakdown...). In this case the other PC automatically enters the standalone operating mode. Furthermore, in the situation where transmission of the event file encounters the problem of a congested Ethernet network, the file is stored in the acquisition PC for later transmission.
Finally, in the event of a mains failure, the complete system is automatically restarted once the power supply is re-established. The capacity of the hard disks of the 2 PCs is tested before anything is written to them during communication difficulties. Backup onto magnetic tape is then initiated. Handling of interrupt, breakdown and communication problem messages is integrated in the system, and can be consulted at any time. These precautions are essential in order to ensure remote seismic monitoring of the site with a minimum risk of system failure and therefore of lost data. Finally it should be noted that this system has been designed to permit the parallel connection of several acquisition stations controlling several seismic sub-networks which are monitoring distant zones of interest and of very different dimensions.

\subsection{Data processing}

The automatic processing operated by the network multitasking machine enables a report to be issued automatically for each event. Interactive processing, from any machine connected to the network, can therefore be linked up a few moments after the acquisition for verification of the calculated parameters (Fig.3). The permanent updating of a files system of the database type, on a monthly basis in this case. permits the statistical study, a posteriori, of the fundamental parameters characterising the microseismic activity induced by different mine workings.

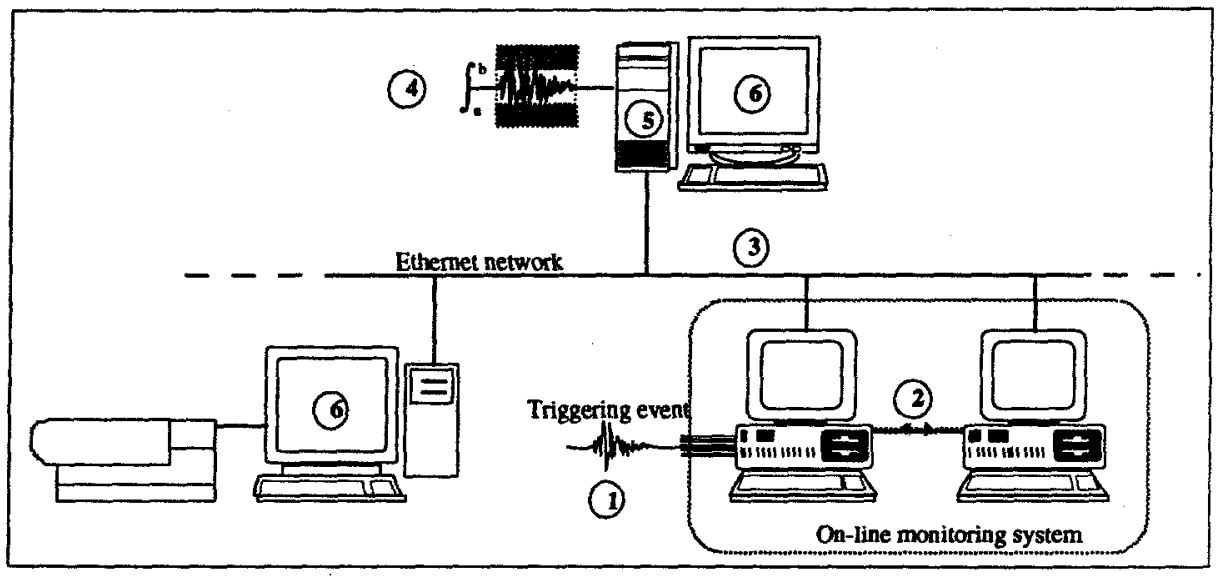

Figure 2 : Dual PC based, no blind time, automatic monitoring and processing system. Steps can be described as 1) trigerring microseismic event detected 2) Data acquisition on PC Master shifting to PC Slave and pre-processing of waveforms 3) Data transmision on multitasking machine 4) full waveform analysis 5) Data storage and Data-base oriented files up-date 6) Interactive processing of seismic events for checking, automatic edition of report, and mapping. 


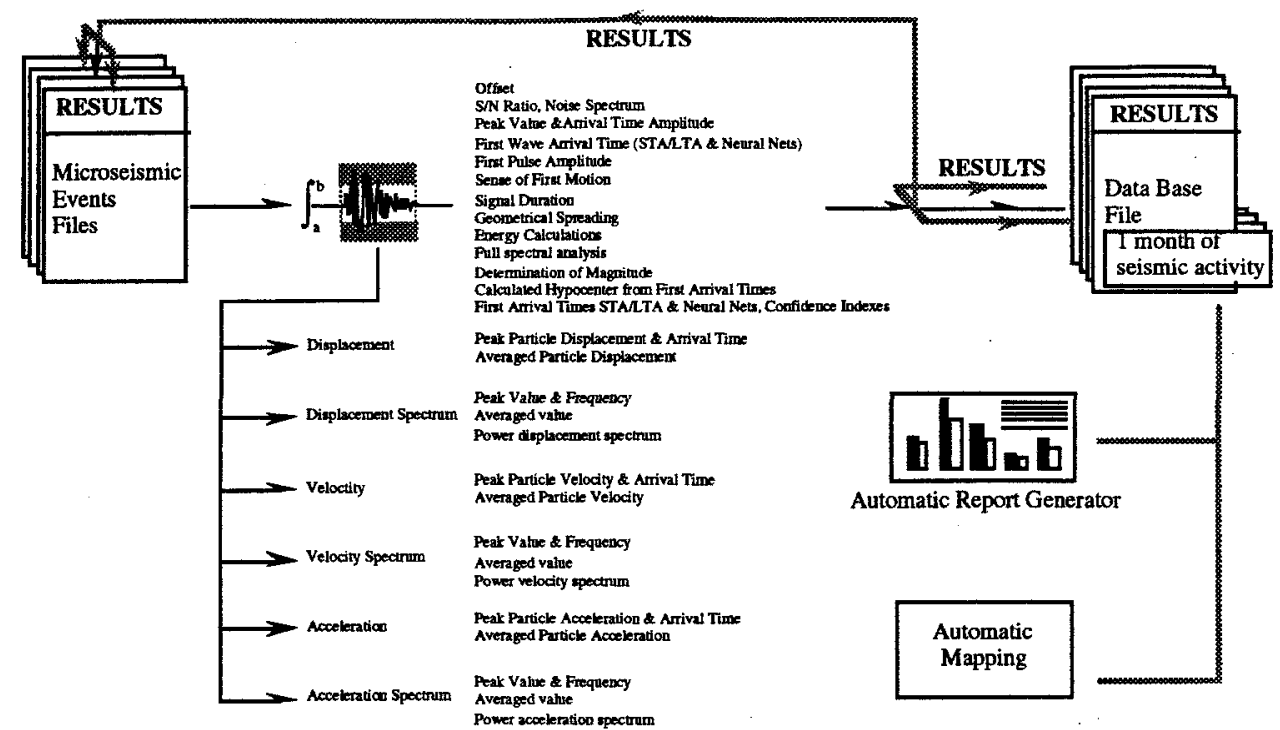

Figure 3 : Real-time, full automatic waveform analysis: all physical, calculated results are stored or up-dated in both seismic event file and data-base oriented file.

Interactive processing, in a high-level graphics environment, enables the operator to verify and/or correct the calculated parameters, in particular the location of the hypocentre of the tremors. The location calculation, based on automatic picking of first $P$ wave arrival times, is in fact very sensitive to the quality of the signal-to-noise ratio of the seismograms. It is necessary therefore to be able to validate quickly any tremor located in a suspect zone. The hypocentre calculation method is based on total inversion (Tarantola and Valette, 1982), with automatic establishment of probability in space.

\subsection{Accuracy of automatic location}

The location of the seismic tremors is an essential parameter for the interpretation of the microseismic activity of each of the workings. The absolute accuracy of the calculation of the hypocentre depends on different criteria such as the geometric configuration of the network, knowledge of the velocities and paths of the wave propagations, the sampling frequency of the acquisition system and the reliability of the picking. Experience clearly shows that the second point, i.e. determination of an adequate velocity model, is crucial to obtaining good accuracy of the coordinates $(\mathrm{X}, \mathrm{Y}, \mathrm{Z}, \mathrm{T})$ of each event.

\section{IMPLEMENTATION OF AN INCLINED MULTILA YERED MODEL}

The velocity model initially used for the Provence basin was a homogeneous velocity model. During 1992 it rapidly became obvious that this model was introducing systematic biases of more than 150 metres relative to the epicentres in the South-East direction, and this applied to each area of activity. Similarly, the depth of the hypocentres almost always placed the events below the level of the mined layer which seemed to contradict the expected mechanisms of roof caveins, largely observed or experienced in the workings. A parameter study of the mean propagation velocity had not made it possible to improve the inaccuracies found.

In 1992, the Laboratoire de Détection et Géophysique (LDG) deployed a mobile network of four extra surface stations, this network being coupled to the permanent network (16 sensors in total). One of the main objectives of this campaign of measurements was to estimate the errors made by the homogeneous model (Nicolaset al, 1993) thanks to a better azimuth coverage of the monitored zone. It was possible in this way to record approximately 260 microseismic events over the 10 days of the campaign. The local magnitude of these tremors is between 1.5 and 2.2. The low mining activity over the period in question meant that it was not possible to record events of a higher magnitude. 
Given the fact that calibration blasts are not permitted in coal mines, the development of a new velocity model was based on sources of information from:

- a study conducted by the LDG in the Provence basin in 1989;

- geological data available from the engineering department of the mine;

- recordings of quarry blasts carried out outside the permanent network;

- seismic core drilling carried out in 1982.

Meticulous and cross analysis of this data has made it possible to construct an inclined multilayered velocity model (Fig.4) for which corrections of stations, calculated by the Pavlis-Booker method, have been put forward. The introduction of a geological model comprising three levels and a half-space clearly corrects the epicentres, while the station corrections appreciably improve the calculated depths especially at the centre of the network (Nicolas et al, 1933).

Nevertheless, a method of calibrating the model has been adopted using the recordings of dynamic phenomena associated with observed damage as «natural mines blasts».

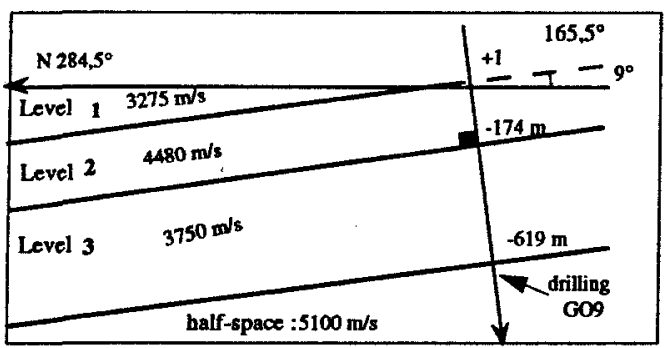

Fig.4: Inclined multilayered velocity model (model B) comprising three levels and a half-space.

\section{CALIBRATION OF THE MODEL}

At Houillères de Provence a rockburst is a sudden and powerful rupture of the coal seam accompanied by violent concussion which can be perceived relatively far away in the mine and can be felt at the surface. When associated with microseismic events of a magnitude greater than or equal to 2.3 they can be used as calibration references in as much as it is assumed that the precise location based on the arrival times of $P$ waves corresponds either to the observed damage or a structure considered to be active (fault, quarry face...).
Between 1991 and 1993, 18 rockbursts or dynamic phenomena of a lesser degree have been recorded at the Provence colliery. The precise location of these events compared with that of observed focuses makes it possible therefore to test the usefulness of an inclined sloping multilayered model for the determination of seismic focuses.

Three propagation models have been tested on the basis of this series of 18 events. These models are: the homogeneous velocity model (designated hereinafter as model $A$ ), the inclined multilayered velocity model recommended by the LDG (model B) and finally the latter model complete with station corrections (model C) (Table 1).

Figures $5 \mathrm{a}$ and $5 \mathrm{~b}$ show all the relocations for 2 events from the 18. The results have revealed three distinct trends :

1- Model A moves the tremors in the south east away from any possible focus (observed damage, face, faults);

2- Model B moves the location to the west;

3- Model $\mathrm{C}$ locates the tremors in the south-east.

None of these three models makes it possible to match the theoretical focuses to the apparent focuses for the 18 events studied. A parameter study of the inclined multilayered model has been carried out to improve these results further. The parameters - a priori 9 in number - are: the 3 levels, the 4 velocities, the azimuth and the slope of the levels.

\subsection{Design of a new velocity model}

In order to refine the modelling of the structure of the Gardanne basin, all the data on the structure of the rocks and seismic velocities have been reconsidered and supplemented.

On the subject of geological data, the work by Glintzboeckel (1980) on the interpretation of 18 exploratory drillings carried out in the region have permitted a detailed analysis of the local lithostratigraphy. For the propagation velocities, the work by Bideaud (1980) and Lebreton (1980) has provided values for different geological levels. The main results for each of the four layer levels in question can be summarised as follows: 
Table 1: Main parameters defining each of the velocity modeis A, B and C.

\begin{tabular}{|l|c|c|c|}
\hline \multicolumn{1}{|c|}{ model } & A & B & C \\
\hline number of layers & 1 & 4 & same as B \\
dip/dip direction & half-space & $165^{\circ}-9.7^{\circ}$ & B \\
velocity & $4000 \mathrm{~m} / \mathrm{s}$ & $3275-4480-3750-5100 \mathrm{~m} / \mathrm{s}$ & B \\
depth of interface & $0 \mathrm{~m}$ & $80-250-750 \mathrm{~m}$. & B \\
corrections & no & no & yes \\
\hline
\end{tabular}
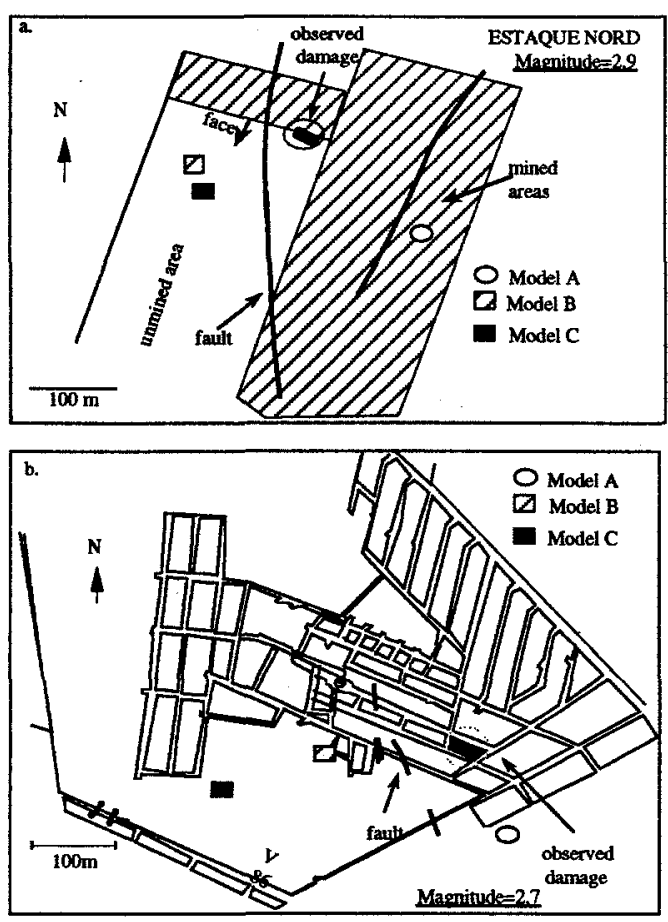

Fig.5: Compared location of rockburst with velocity models A, B, C.
Level I: The upper Fuvelian and Begudian calcareous series are very well represented at this level (Fig.6) (exploratory drillings GS1 and S11) in direct relationship to the overthrust fault of La Diote to the south of the deposit. In the north we find argillaceous marl sequences traversed by calcareous packets. Lebreton (1980) obtained powerful velocities between $4000 \mathrm{~m} / \mathrm{s}$ and $5000 \mathrm{~m} / \mathrm{s}$ for the calcareous levels. A quarry blast indicates a velocity of $3717 \mathrm{~m} / \mathrm{s}$, in apparent contradiction to the results of another quarry blast indicating a velocity of $3200 \mathrm{~m} / \mathrm{s}$. Every consideration having been taken into account, the velocity of $3717 \mathrm{~m} /$ $s$ has nevertheless been retained. The thickness of this level has not been challenged.

Level II: (depth at point GS1: $380 \mathrm{~m}$ ). This consists exclusively of upper Begudian calcareous series (Fig.6). A quarry blast indicates a propagation velocity of 4480 $\mathrm{m} / \mathrm{s}$, a value in agreement with that supplied by a seismic core drilling. It was decided therefore to keep the parameters of this level.

Level III: The comparison of the geological and seismic data does not offer a clear choice for the wave velocity and the thickness of level III. Nevertheless, the strong representation of upper Begudian, consisting essentially of marl, makes it possible to envisage small

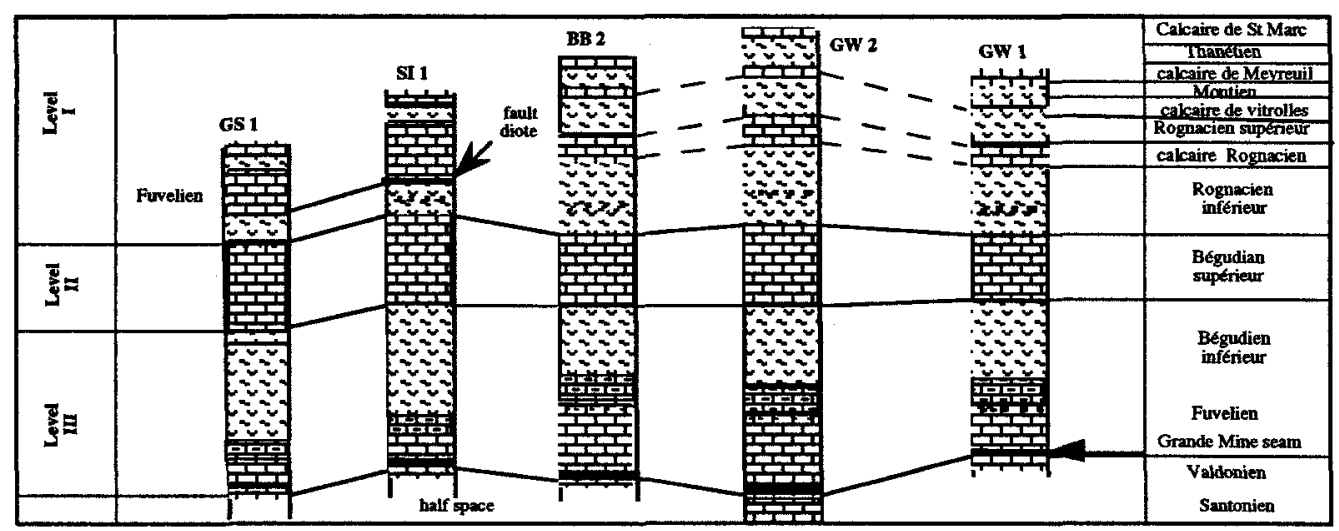

Fig.6: Correlation of the local lithostratigraphy from exploratory drillings: GS1, S11, BB2, GW2, GW1. 
velocity contrasts. Because the boundary between the lower Begudian (marls) and the Fuvelian (limestone) is not easily identifiable, we establish therefore a lower limit for the level III below the mined layer (Fig.6). Based solely on the geometrical interpretations we propose a velocity of $3200 \mathrm{~m} / \mathrm{s}$, a value smaller than that already used of $3750 \mathrm{~m} / \mathrm{s}$.

Half-space: This last level consists of a strongly calcareous assembly traversed by a thin clay level. This data justifies a strong velocity for this layer, i.e. that of $5100 \mathrm{~m} / \mathrm{s}$ put forward in the old model which seems to be the most suitable.

\subsection{Numerical test}

For each theoretical focus calculated by inversion, the root-mean-square (R.M.S.) of the residual times (difference between the theoretical and picked propagation times) gives an indication of the conformity of the data with the model. We analysed the variation of the R.M.S. as a function of several parameters of the new velocity model (model D). For level 1 we advanced the velocity progressively from $3000 \mathrm{~m} / \mathrm{s}$ to $4100 \mathrm{~m} / \mathrm{s}$ in increments of $100 \mathrm{~m} / \mathrm{s}$. For each value, 188 located events supplied an average R.M.S. This is the minimum value for the velocity of $3700 \mathrm{~m} / \mathrm{s}$ (Fig.7): this result is in agreement with the recommended value of $3171 \mathrm{~m} / \mathrm{s}$. For level III we varied the velocity from $2700 \mathrm{~m} / \mathrm{s}$ to $4700 \mathrm{~m} / \mathrm{s}$. The minimum overall R.M.S. appears in a range from $3000 \mathrm{~m} / \mathrm{s}$ to $3200 \mathrm{~m} / \mathrm{s}$ (Fig.7). This result is also in agreement with the previous results which suggest a value of $3200 \mathrm{~m} / \mathrm{s}$. For the halfspace we varied the velocity progressively from 4200 $\mathrm{m} / \mathrm{s}$ to $5500 \mathrm{~m} / \mathrm{s}$; the minimum R.M.S. is in the range from $5100 \mathrm{~m} / \mathrm{s}$ to $5300 \mathrm{~m} / \mathrm{s}$, and this result verifies the high velocity of $5100 \mathrm{~m} / \mathrm{s}$ obtained by the geological interpretations.

Although currently being used, this type of numerical test is difficult to interpret since only one space coordinate of the solutions is taken into consideration at any one time. Nevertheless, it is essential for confirming the values obtained from associated analyses.

\section{LOCATIONSOF ROCKBURSTS COMPARED (MODEL D)}

For the 18 rockbursts listed, we made a systematic comparison of the calculated focus and the observed focus with an accuracy from 0 to 50 metres with respect to the epicentres (Figs. 8a and 8b). At depth, the

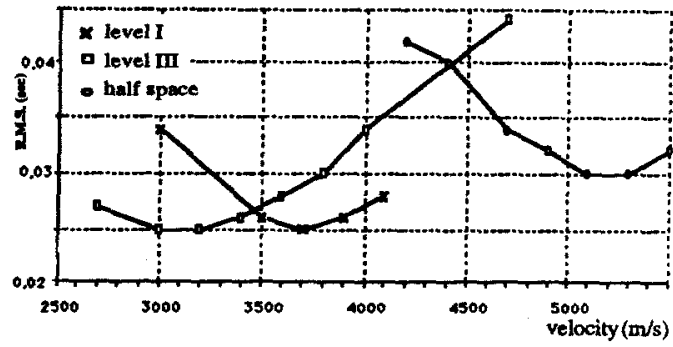

Fig.7 : Analysis of the average R.M.S. as a function of the propagation velocity from a population of 188 microseismic events.
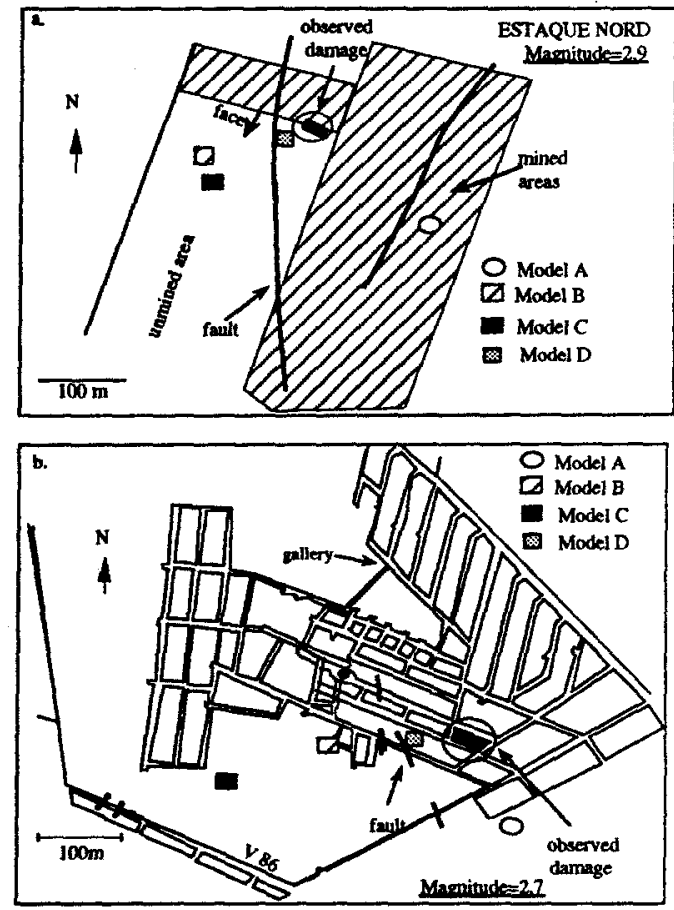

Fig. 8: Comparison of rockbursts located with velocity models A $B, C$ and the new velocity model D.

calculated focuses are located at the coal seam level with an accuracy of 0 to $25 \mathrm{~m}$.

Encouraged by these very satisfactory results, we proceeded to compare locations of a "cloud" of 200 microseismic events which are representative of the daily microseismic activity in the mine. For each model the position of the tremors relative to the working face reveal the following results: Model A shifts the location of the cloud towards the west, model B (the 


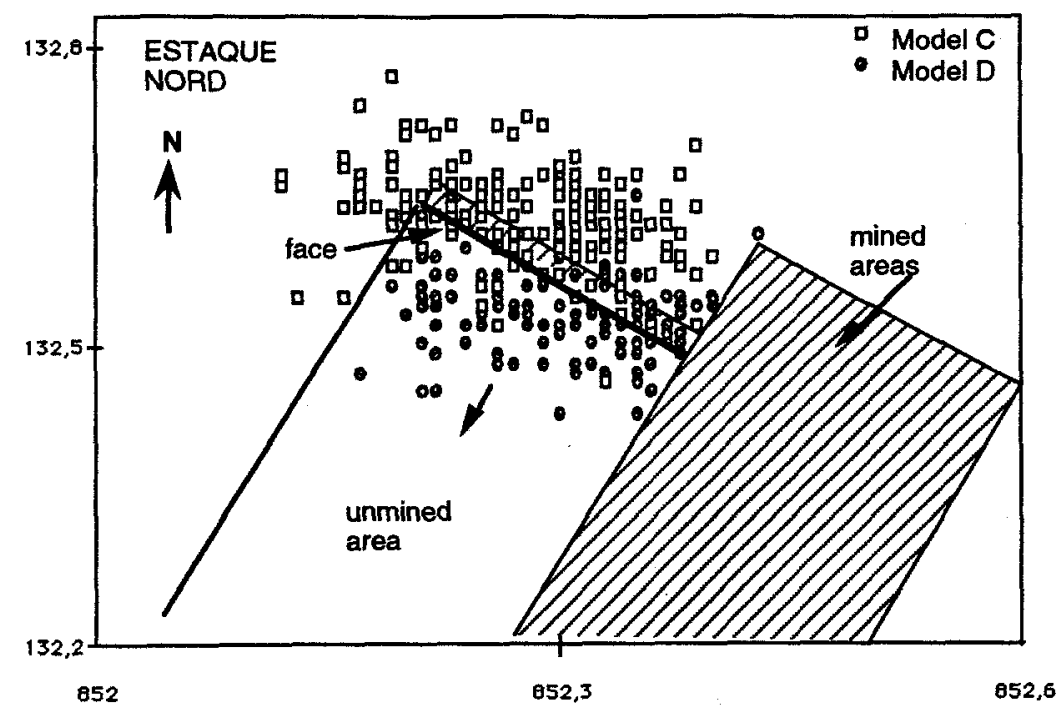

Fig. 9 : Location of 200 tremors compared: model B locates the cloud at the back of the face and model (new multilayered model) locates the cloud at the level of, and in front of the face.

multilayered model) positions the cloud in front of the face, model $\mathrm{C}$ (multilayered with station corrections) positions the cloud at the back of the face and the model D (new multilayered model) concentrates the cloud in front of the face (Fig.9). At depth, in all cases, the cloud is located at the level of, and above, the coal seam; only the homogenous model disperses the hypocentres below the coal seam (between 1000 and 1600 metres depth).

Syrek and Kijko (1988) obtained similar results for coal mines in Poland, with seismic tremors located rather at the level of, and in front of the face. These results are in agreement with the results obtained by the new multilayered velocity model.

\section{CONCLUSIONS}

In many respects, location accuracy and space-distribution of the mine-induced tremors are two important, sensitive parameters in the interpretation of the microseismic activity provided to the mine industry. The development and testing of an inclined multilayered velocity model for wave propagation assessment is a very important part of the quality of this interpretation. It provides for two essentials aims: accuracy of the hypocentre locations, stability in time of the model with the underground activity moving westwards, and deeper. This model has been tested against damages associated with local, underground dynamic events recorded by the seismic array. Results of locations have been considerably improved by this model taking into account the main features of the geology of the basin. Installation on the site for daily routine of this clearly makes possible a better scientific analysis of the rock mass response, as well as a more comprehensive assessment on rockburst hazard to the benefit of the mine.

\section{Acknowledgements}

We would like to thank the Engineering Services of the Provence Operational Unit of the HBCM for the active support they provided throughout the duration of this study. We would also like to thank Messrs. Bennani and Lizeur, computer systems engineers (INERIS) for the numerical developments carried out and for their invaluable help.

\section{References}

Allen V., 1978. Automatic earthquake recognition and timing from single traces. Bull. Seism. Soc. Am. 68, $\mathrm{n}^{\circ} 5$, pp 1521-1532.

Ben Slimane K., 1990. Sismicité induite et exploitation. Etude CECA ${ }^{\circ}$ 7220-AF/308. Internal Report, INERIS, Nancy pp 45. 
Ben Slimane K., Besson J.C., Mandereau G., Chambon C., 1990. La surveillance sismique : un outil d'aide a la planification des chantiers miniers sujets aux phénomènes dynamiques. 3ème Colloque PolonoFrançais, Wroclaw. Studio Geotechnica et Mechanica, Vol XI n ${ }^{\circ} 1$ et 2, pp 55-68.

Bigarré P., Tinucci J., Ben Slimane K., 1993. Dimensional modelling of fault-slip rockbursting. Proc. 3rd Int. Symp. "Rockbursts and seismicity in Mines, ed. C. Fairhurst, Balkema, pp 315-319.

Bertil D., Cansi Y., Descloitres M., 1987. Etude de la sismicité du bassin de Gardanne, Internal report, Laboratoire de détection et de Géophysique C.E.A.

Bigarré P., Lizeur A., Bennani M., 1994. Integrated software package for microseismic monitoring. To be published.

Bideaud M., 1980. Une étude sismique dans le bassin de l'Arc. Revue Industrie Minérale Suppl. Juin 1980.

Dodo Amadou A., Bigarré P., Mathieu E., 1994. Amélioration du pointé automatique d'arrivée d'onde. To be published.

Gibowicz S.J., 1990. Keynote lecture : the mechanism of seismic events induced by mining. 2nd Int. Symp. Rockbursts and Seismicity in Mines, ed. C. Fairhurst, Balkema, pp 3-27.

Glintzboeckel Ch., 1980. Le gisement de charbon du bassin de l'Arc (Houillères de Provence). Revue Industrie Minérale Suppl. Juin 1980.

Lebreton F., 1980. Apport des diagraphies à l'étude de la subsurface dans les sondages de Gardanne. Revue Industrie Minérale, Suppl. juin 1980

Mathieu E., 1989. Apport de l'écoute sismoacoustique pour la surveillance des chantiers miniers affectés de coups de terrains - Application au cas des tailles de l'Unité d'Exploitation de Provence. Thèse de Doctorat, Institut National Polytechnique de Lorraine.

Nicolas M., Cansy Y., Plantet J.L., 1993. Amélioration de la précision de localisation des événements enregistrés dans le bassin de Gardanne, Bouches du Rhône. Internal report, Laboratoire de Détection et de Géophysique, C.E.A., pp 13.
Pavlis G. and Booker J., 1983. Progressive Multiple Event Location (PMEL). Bull. Seism. Soc. Am. 73, $n^{\circ}$ 6, pp 1753-1777.

Revalor R., 1991 La maîtrise des coups de terrains dans les exploitations minières. Thèse de Doctorat, Institut National Polytechnique de Lorraine.

Senfaute G., Bigarré P., 1994. Optimisation de la localisation des foyers sismiques a l'U.E. Provence. Application aux phénomènes dynamiques. Internal report, INERIS, Nancy, pp 53.

Syrek B., Kijro, 1988. Energy and frequency distributions of mining tremors and their relations to rockburst hazard in the wujek coal Mine, Poland. Acta Geophys, Pol. 36.

Tarantola A. and Valehe B., 1982. Generalized Non Linear Inverse Problems Solved Using the Least SquaresCriterion. Reviews of Geophys. and Space Physics. Vol. 20, n², pp 219-232.

Tarantola A. and Valette B., 1982. Inverse Problems : Quest for information. Journal of Geophysics, pp 159170. 